\title{
Protective role of dexmedetomidine in unmethylated CpG-induced inflammation responses in BV2 microglia cells
}

\author{
Chen Chen ${ }^{1,2}$, Yanning Qian ${ }^{1}$ \\ ${ }^{1}$ Department of Anesthesiology, First Affiliated Hospital of Nanjing Medical University, Nanjing, Jiangsu, 210000, ${ }^{2}$ Department \\ of Anesthesiology, The First People's Hospital of Changzhou, Changzhou, Jiangsu, 213000, China
}

\begin{abstract}
Unmethylated CPG DNA, as a stimulatory molecule, has potent pro-inflammatory effects in the central nervous system (CNS). Dexmedetomidine (DEX) has been confirmed to exert anti-inflammatory effects in CNS. Our study was aimed to explore the effects of DEX on tumor necrosis factor- $\alpha$ (TNF- $\alpha$ ) expression in unmethylated CPG DNA-challenged microglia. In vivo, after 3 d intracisternal injection of ODN1668, we evaluated the severity of meningitis with or without DEX via pathobiology method and detected the expression of TNF- $\alpha$ from molecular and protein levels. In vitro, we explored whether the ODN1668 could activate microglia to express TNF- $\alpha$ and the inhibition mechanism of DEX. Our results demonstrated that DEX could alleviate the severity of ODN1668-induced meningitis. And while BV2 microglia was stimulated by ODN1668 for different time, TNF- $\alpha$ was increased in mRNA and protein levels but the effect was attenuated by DEX via decreasing phosphorylated AKT and ERK.
\end{abstract}

Key words: DEX, unmethylated CPG DNA, microglia.

\section{Introduction}

Unmethylated CpG motifs in bacterial DNA exert stimulatory effects on murine and human lymphocytes to secret interleukin-6 (IL-6), interleukin-12 (IL-12), interferon- $\gamma$ (IFN- $\gamma$ ) and tumor necrosis factor- $\alpha$ (TNF- $\alpha)[8,26,27,33,55]$. Synthetic oligodeoxynucleotides with immunostimulatory $\mathrm{CpG}$ motifs also have these effects [52]. Toll like receptor-9 (TLR-9) is essential for CpG DNA to activate innate immune response [23]. It has been proven that bacterial DNA could cause many diseases, such as arthritis [11], septic shock [46], meningitis [12] and skin inflammation [32]. In the central nervous system, unmethylated CpG DNA could activate microglia and astrocytes to express TNF- $\alpha$, IL-12 and NO $[9,48]$, and it is believed that exacerbation of meningitis caused by increased levels of these inflammation cytokines leads to the damage of the blood-brain barrier (BBB) $[39,40]$.

Tumor necrosis factor $\alpha$ is a homotrimeric transmembrane protein that plays an important role in innate immune defense and maintenance of homeostasis at the cellular, tissue and organ levels [49]. Excessive TNF- $\alpha$ in the central nervous system has been verified in patients and animal models of a wide range of CNS pathologies such as Alzheimer's disease (AD) [17], Parkinson's disease (PD) [4], multiple sclerosis (MS) [24] and meningitis [29]. In the animal model, circulating TNF- $\alpha$ could cross the BBB into brain parenchyma by a special saturable transport system [21]. Inflammatory stimuli such as 
LPS [58], CpG DNA [9], cytokines could induce TNF- $\alpha$ production by additional CNS cell types, especially microglia, which is recognized as an abundant source of TNF- $\alpha$ [43]. In the CNS inflammatory diseases, TNF- $\alpha$ could induce leukocyte adhesion to cerebral vessels through upregulating expression of adhesion molecules such as VCAM and ICAM [37], and also could damage BBB [10]. Oligodendrocyte apoptosis and neuroinflammation could be induced by overexpression of TNF- $\alpha$ from glia [38].

Microglia, resident macrophages in the CNS, are sensitive to and activated by trauma, neurodegenerative diseases and infection [36]. Apoptosis of dopaminergic neurons could be mediated by LPS-activated microglia [14]. The pro-inflammation cytokines secreted by microglia are IL-1, IL-6, IL-10, IL-12, TNF- $\alpha$, TGF- $\beta$ and chemokines [41]. Microglia play distinctive roles in different diseases, it has been reported that microglia have a neuroprotective role in Alzheimer's disease [28].

Dexmedetomidine (DEX), a highly selective and potent $\alpha 2$-adrenoreceptor agonist, provides excellent sedation, analgesic and anxiolytic effects [3]. A lot of evidence has shown that DEX exerts anti-inflammatory effects [54]. DEX could ameliorate intestinal injury induced by CLP [7] and attenuate LPS-induced lung injury [53]. However, the mechanisms of neuroprotective effects of DEX in microglia activation have not been elucidated. Thus, the purpose of this study was to evaluate the effects of DEX on CpG DNA-induced microglia activation and illuminate possible mechanisms of its neuroprotective actions.

\section{Material and methods}

\section{Animals}

Male C57BL/6 mice (6-7w) were obtained from the Nanjing University Animal Center. All experimental procedures were conducted with the approval of the Ethics Committee of Nanjing Medical University and in accordance with the Guide for the Care and Use of Laboratory Animals (U.S. National Institutes of Health publication No. 85-23, National Academy Press, Washington DC, revised 1996).

\section{ODN1668 and ODN1720}

Oligonucleotides 1668 and 1720 were synthesized by Invitrogen ${ }^{\text {TM }} .1668$, 5'-TCC ATG ACG TTC CTG ATG CT-3'; 1720, 5'-TCC ATG AGC TTC CTG ATG CT-3'.

\section{Injection protocol}

Mice were anesthetized by chloral hydrate, after shaving and disinfection of the injection area, $10 \mu \mathrm{l}$ of ODN was injected intracisternally into mice. Three days after injection, mice were sacrificed and brains were collected.

\section{HE staining and immunohistochemical staining}

Brain tissues were fixed in formalin and dehydrated by concentration gradient of ethanol and embedded into paraffin, and then were transversely cut into $5 \mu \mathrm{m}$ sections, which were subjected to be stained with hematoxylin and eosin. The brain sections were dewaxed by Xylene, then hydrated, after heat antigen retrieval, the sections were labeled with anti-TNF- $\alpha$ antibody (R\&D), biotin-conjugated goat anti-rabbit $(\mathrm{KPL})$ as the secondary antibody labeled the primary antibody and combined with Elite AB (Vector), at last $D A B$ were used for color development.

\section{RNA extraction and real-time PCR}

Total RNA was extracted from brain tissues and cells using Trizol Reagent (Takara) according to the manufacturer's instructions. The concentration of RNA was confirmed using Ultra Micro-ultraviolet spectrophotometer (One drop OD1000, China). All of RNA was reverse-transcribed using the PrimeScript ${ }^{\circledR}$ RT reagent Kit (TaKaRa) according to the manufacturer's instructions. Real-time PCR using Takara (Takara) was carried out on the 7300 System (ABI) for the detection of PCR products.

TNF- $\alpha$ reverse: 5'-ACATTCGAGGCTCCAGTGAATTCGG-3'; TNF- $\alpha$ forward: 5'-GGCAGGTCTACTTTGGAGGTCATTGC-3'.

\section{Western-blot}

RIPA was used for cells lysis, and then the extracted protein concentration was determined with BCA methods. The protein samples were loaded into 10\% SDS-PAGE and transferred to the PVDF membrane (polyvinylidene fluoride), then the PVDF membrane was incubated with anti-p-JNK, JNK, p-AKT, AKT, p-ERK and ERK antibodies respectively overnight at $4^{\circ} \mathrm{C}$, next the PVDF membrane was incubated with anti-rabbit antibodies conjugated with HRP, immunocomplex was detected by the enhanced horseradish peroxidase/luminal chemiluminescence system (ECL). 


\section{Cell Proliferation Assay}

Cell counting Kit-8 (CCK-8) was applied to cell proliferation. The BV2 cells were cultured in triplicate in 96-well plates treated by $0.5 \mu \mathrm{M}, 1 \mu \mathrm{M}, 5 \mu \mathrm{M}$ and $10 \mu \mathrm{M}$ DEX for $6 \mathrm{~h}$, then cell proliferation was determined according to the manufacturer's instructions (Beyotime, China).

\section{Cytokine Bead Array}

The Cytokine Bead Array was used for measurement of TNF- $\alpha$ in the supernatants of BV2 cell stimulated by $16680 D N$ or control. $50 \mu$ of each sample was mixed with $1 \mu$ l of TNF- $\alpha$ capture beads for $1 \mathrm{~h}$ at room temperature then added into $1 \mathrm{ul}$ of $\mathrm{PE}$ detection reagent for $1 \mathrm{~h}$ at room temperature in the dark. Beads were washed with wash buffer and centrifuged at $200 \mathrm{~g} \times 5 \mathrm{~min}$, discarded the supernatants. The pellets were resuspended with $200 \mu$ of wash buffer and assayed on FACS Calibur (BD Biosciences). The concentration of TNF- $\alpha$ was determined by the software provided.

\section{Immunofluorescence}

The stimulated BV2 cells were fixed with $2 \%$ paraformaldehyde for $10 \mathrm{~min}$ at room temperature, the primary antibodies Iba-1 (Wako) and TNF- $\alpha$ (R\&D) co-incubated with BV2 cells at $4^{\circ} \mathrm{C}$ overnight, then the secondary antibodies, anti-rabbit Alexa Fluor 488 and anti-goat Alexa Fluor 584 co-incubated with BV2 cells at room temperature for $1 \mathrm{~h}$, DAPI was used for labeling nucleus. The images were obtained with Zeiss microscope.

\section{Isolation of primary microglia}

Microglia of newborn mice were prepared as described [50]. Briefly, brains of newborn C57BL/ 6 mice were dissected and dissociated. The cells were seeded in DMEM-F12 medium containing 10\% FBS with $75 \mathrm{~cm}^{2}$ culture flask. On day 14 , cultures were agitated on a rotary shaker at $240 \mathrm{rpm}$ for $3 \mathrm{~h}$ at $37^{\circ} \mathrm{C}$. Microglia were collected from the supernatant.

\section{Assessment of severity of meningitis}

The severity of meningitis was scored by a predetermined scheme: score 0 - no meningitis; score 1 - occasional occurrence of inflammatory cells; score 2 - inflammatory cells forming an infiltrate not involving the entire depth of the subarachnoid space; score 3 - inflammatory infiltrate involving the entire subarachnoid space.

\section{Statistical analysis}

All data were analyzed as mean and standard deviation (mean $\pm \mathrm{SD}$ ). Student's $t$-test was used to compare differences followed by paired comparisons. A value of $p \leq 0.05$ was regarded as statistically significant. All statistical analyses were performed using GraphPad Prism version 5.0 (GraphPad Software, San Diego, CA).

\section{Results}

\section{Intracisternal injection of ODN1668 could cause meningitis and activate microglia}

It has been reported that the intracisternal injection of ODN1668 could cause meningitis [10], so ODN1668 was employed in our study, ODN1720 as a control, which contained methylated CpG sequences. The results showed that the mice treated with ODN1668 developed meningitis, but not controls (Fig. 1A). The scores of severity of meningitis were much higher compared with controls (Fig. 1B). It was known that TNF- $\alpha$ played an important role in bacterial meningitis, and the levels TNF- $\alpha$ were obviously elevated in the cerebrospinal fluid $[1,18]$. Similarly, the representative immunohistochemical photographs exhibited an abundant TNF- $\alpha$ expression in the cortex of ODN1668-treated mice (Fig. 1C). To measure the mRNA level of TNF- $\alpha$ in brain tissues, ODN1668-treated brain tissues were analyzed by real-time PCR, and the result showed an obvious increase in TNF- $\alpha$ in ODN1668-treated mice compared with controls (Fig. 1D).

\section{ODN1668 induced BV2 to express TNF- $\alpha$}

We have proved that there was plenty of TNF- $\alpha$ expression in the brain which were administered ODN1668 intracisternally. As mentioned above, microglia were the major resource of TNF- $\alpha$ in CNS [23], so we tested whether ODN1668 could induce microglia to express TNF- $\alpha$ in vitro. Incubation of BV2 cells with ODN1668 for $12 \mathrm{~h}$ stimulated the TNF- $\alpha$ production detected by immunofluorescence (Fig. 2A). Furthermore, real-time PCR showed that ODN1668 time-dependently increased the TNF- $\alpha$ mRNA levels and peaked $6 \mathrm{~h}$ after stimulation (Fig. 2B). It has been 

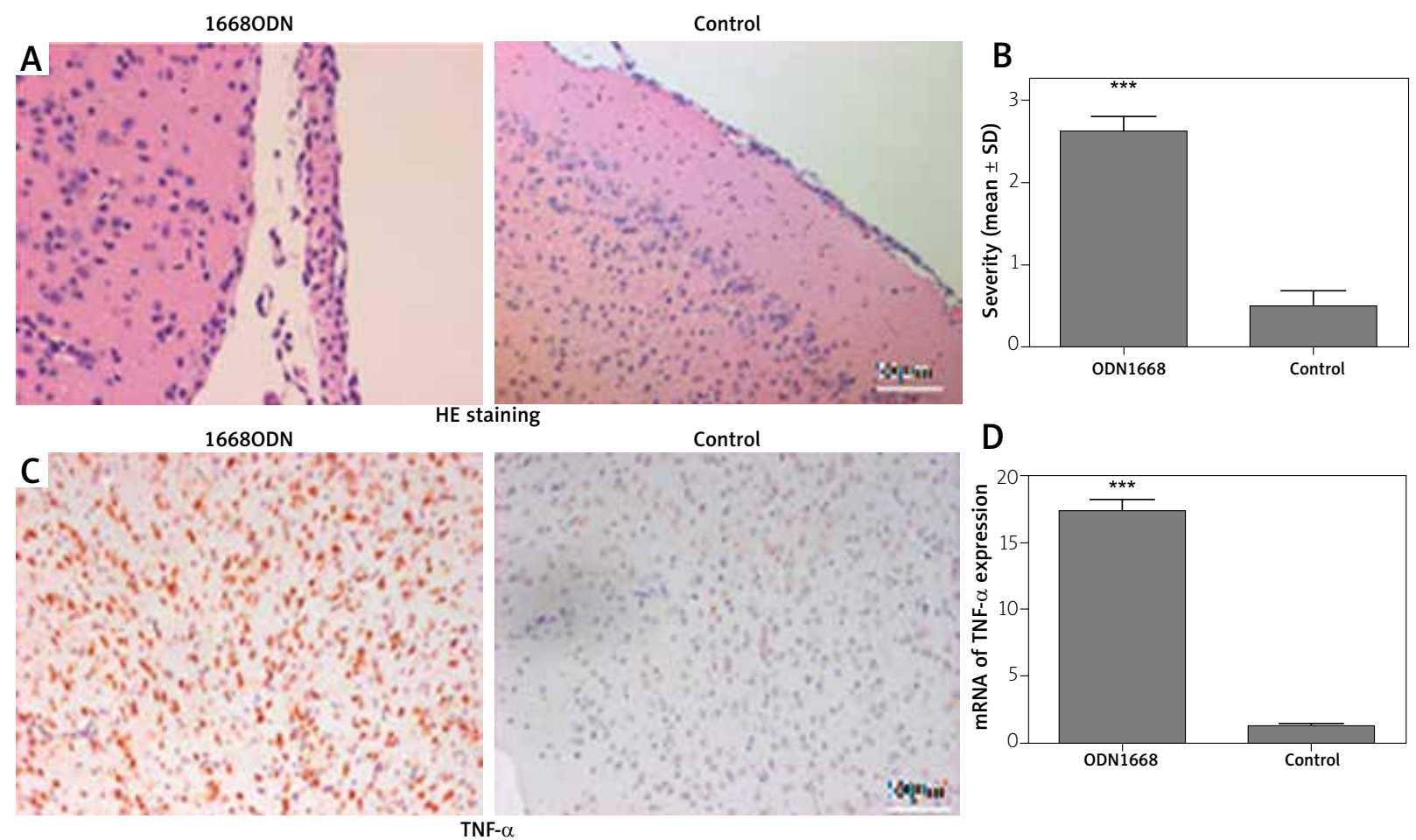

Fig. 1. Intracisternal injection of ODN1668 can activate microglia. A) Histopathology of the brain of a C57BL/ 6 mouse killed $3 \mathrm{~d}$ after intracisternal inoculation of ODN1668 and ODN1720 (1OD) $(n=5$, magnification $\times 200)$. B) Score of meningitis severity in C57BL/ 6 mice treated with ODN1668 for $3 \mathrm{~d}$ (1OD per mouse, $n=5$ ). Values are the mean \pm SD score of inflammatory cell infiltrate score. ${ }^{* \star *} p<0.001$ compared with the control group. C) Immunohistochemical analysis of TNF- $\alpha$ in the brain 3 days after intracisternal inoculation of ODN1668 and ODN1720 $(10 D)(n=5$, magnification $\times 200)$. D) Three days after intracisternal injection of ODN1668, brain tissues were obtained and analyzed by real-time PCR, ODN1720 as control. ${ }^{* * *} p<0.001$ compared with the control group.

reported that microglia could be activated via MAPK pathway [56], so we developed a question whether ODN1668 could activate microglia via this path. To answer it, we stimulated BV2 with ODN1668, western blot results suggested that ODN1668 significantly increased AKT, ERK and JNK phosphorylation and after stimulation the levels of phosphorylation gradually increased, which $\mathrm{p}$-AKT and $\mathrm{p}$-ERK peaked at 20 min and p-JNK peaked at 40 min (Fig. 2C, D).

\section{Dexmedetomidine could inhibit microglia to express TNF- $\alpha$}

CCK-8 assay was used to evaluate to the toxic effects of DEX on BV2. BV2 cells were incubated with different concentrations of DEX $(0.5 \mu \mathrm{M}, 1 \mu \mathrm{M}$, $5 \mu \mathrm{M}, 10 \mu \mathrm{M})$ for $6 \mathrm{~h}$. The results indicated that DEX exerted no obvious toxic effects on BV2 (Fig. 3A). To test whether DEX could depress ODN1668-induced microglia inflammatory response, BV2 cells were pretreated with different concentrations of DEX for
30 min [57], followed by the addition of ODN1668. Real-time PCR results showed that DEX significantly inhibited TNF- $\alpha$ expression in a dose-dependent manner (Fig. 3B). In addition, the primary microglia were isolated from mice and pre-incubated with DEX for 30 min before ODN1668 stimulation for another $6 \mathrm{~h}$. The fluorescence images demonstrated that DEX remarkably inhibited the TNF- $\alpha$ expression in response to ODN1668 (Fig. 3C). Then, we examined whether DEX inhibits TNF- $\alpha$ via the MAPK pathway. Western-blot results demonstrated that DEX inhibited phosphorylated-AKT and ERK levels induced by ODN1668 (Fig. 3D, E).

\section{Injection of dexmedetomidine reduced the generation of TNF- $\alpha$ in vivo}

To know whether DEX could treat ODN1668caused meningitis in vivo, mice received DEX $(50 \mu \mathrm{g} /$ kg, i.c.v.) $30 \mathrm{~min}$ before ODN1668 treatment (1OD, i.c.v.), compared with single treatment with ODN1668 
A TNF- $\alpha$
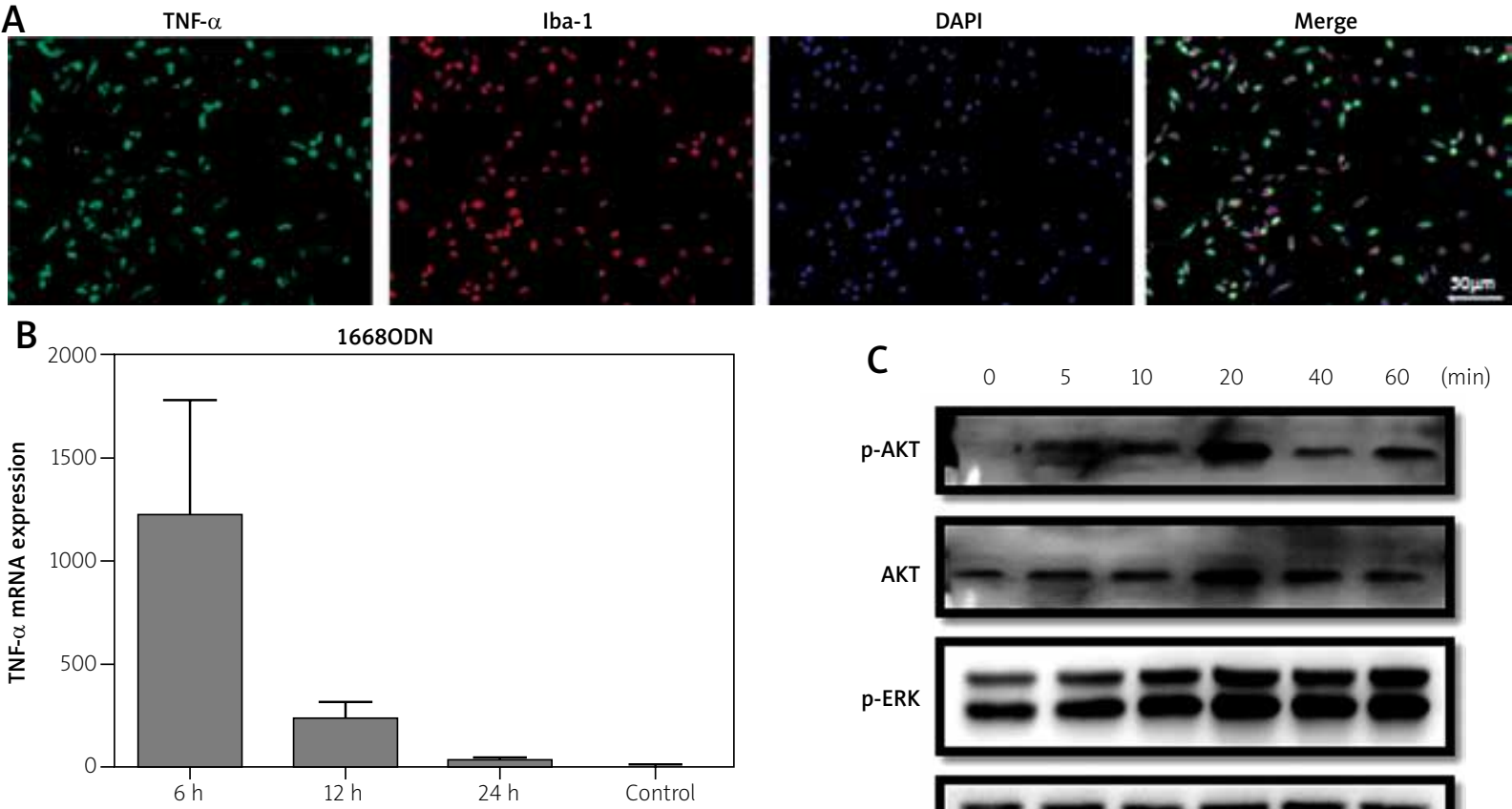

\section{C}



p-AKT

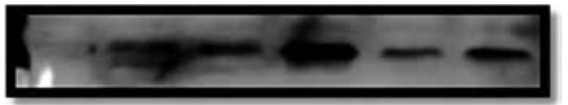

AKT

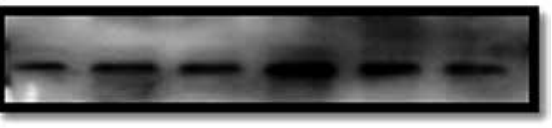

p-ERK

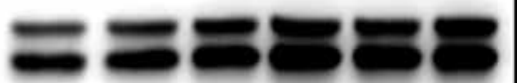

ERK
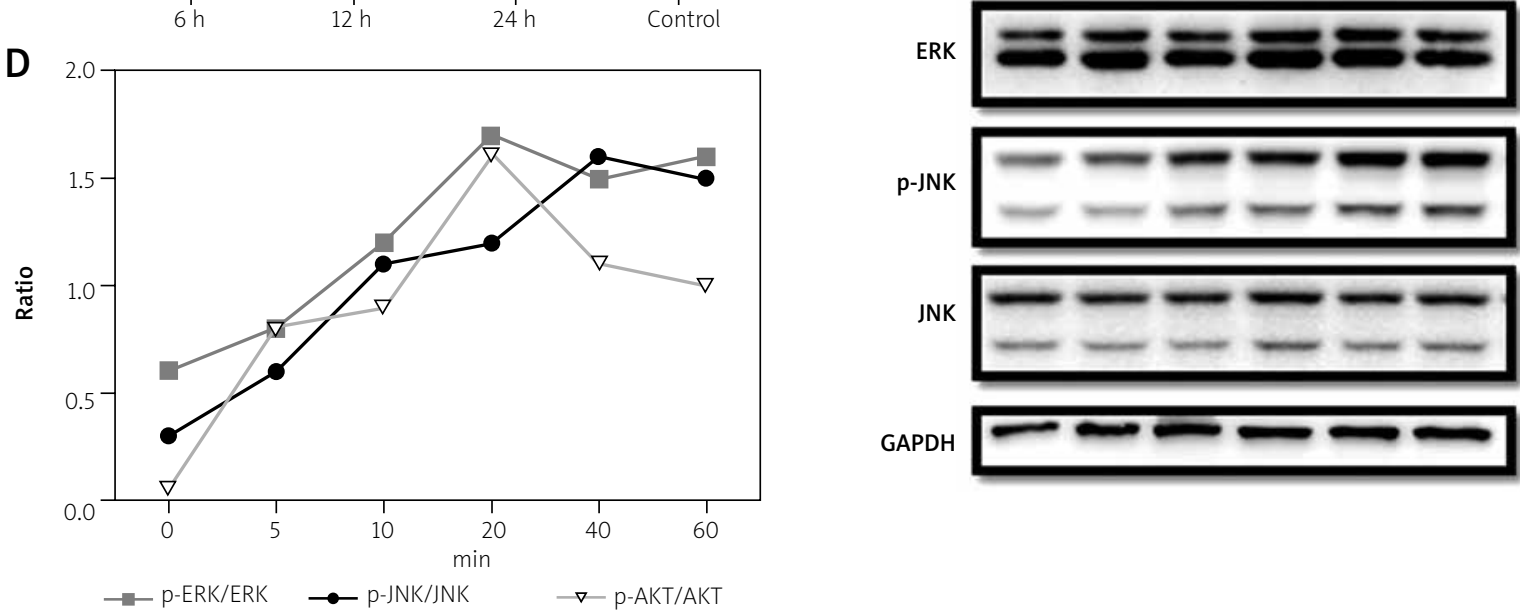

JNK

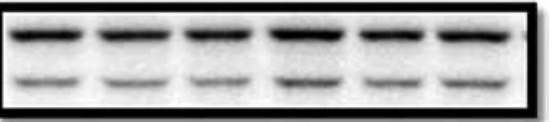

GAPDH

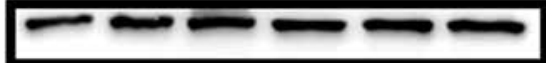

Fig. 2. ODN1668 could induce BV2 strain to express TNF- $\alpha$. A) Representative images of immunofluorescence staining with primary anti-lba-1 and anti-TNF- $\alpha$ antibodies. Immunoreactivities for lba-1 (a marker of microglia, red) or TNF- $\alpha$ (green) were visualized by Alexa Fluor 488-conjugated donkey anti-goat IgG and Alexa Fluor 584-conjugated donkey anti-rabbit IgG. Co-localization of BV2 cells and TNF- $\alpha$, the immunofluorescence images were merged (orange). B) $6 \mathrm{~h}, 12 \mathrm{~h}$ and $24 \mathrm{~h}$ after stimulation by 1OD 16680DN, the TNF- $\alpha$ expression was revealed by real-time PCR. C) Effects of ODN1668-induced phosphorylation of signaling molecule. BV2 cells were treated with ODN1668 for $5 \mathrm{~min}, 10 \mathrm{~min}, 20 \mathrm{~min}, 40 \mathrm{~min}$, and medium as control. The phosphorylation level of AKT, ERK and JNK was analyzed using Western blotting. D) Relative density of p-AKT, AKT, p-ERK, ERK, p-JNK and JNK was analyzed using Photoshop, the ratio of phosphorylation and non-phosphorylation was shown in a line chart.

$(n=5, p<0.05)$. The HE staining (Fig. 4A) and score of severity (Fig. 4B) of two groups showed that the severity of meningitis was significantly alleviated in the DEX group. Next, representative immunohistochemical staining results demonstrated that the level of TNF- $\alpha$ expression was also obviously inhibited by DEX (Fig. 4C).
To further confirm the decrease in TNF- $\alpha$ in DEX-pretreated mice, real-time PCR and immunoblotting were used for quantitative analysis. The real-time PCR and immunoblotting results both demonstrated that the level of TNF- $\alpha$ was decreased significantly in the brains of DEX-pretreated and ODN1668-treated mice (Fig. 4D-F). 

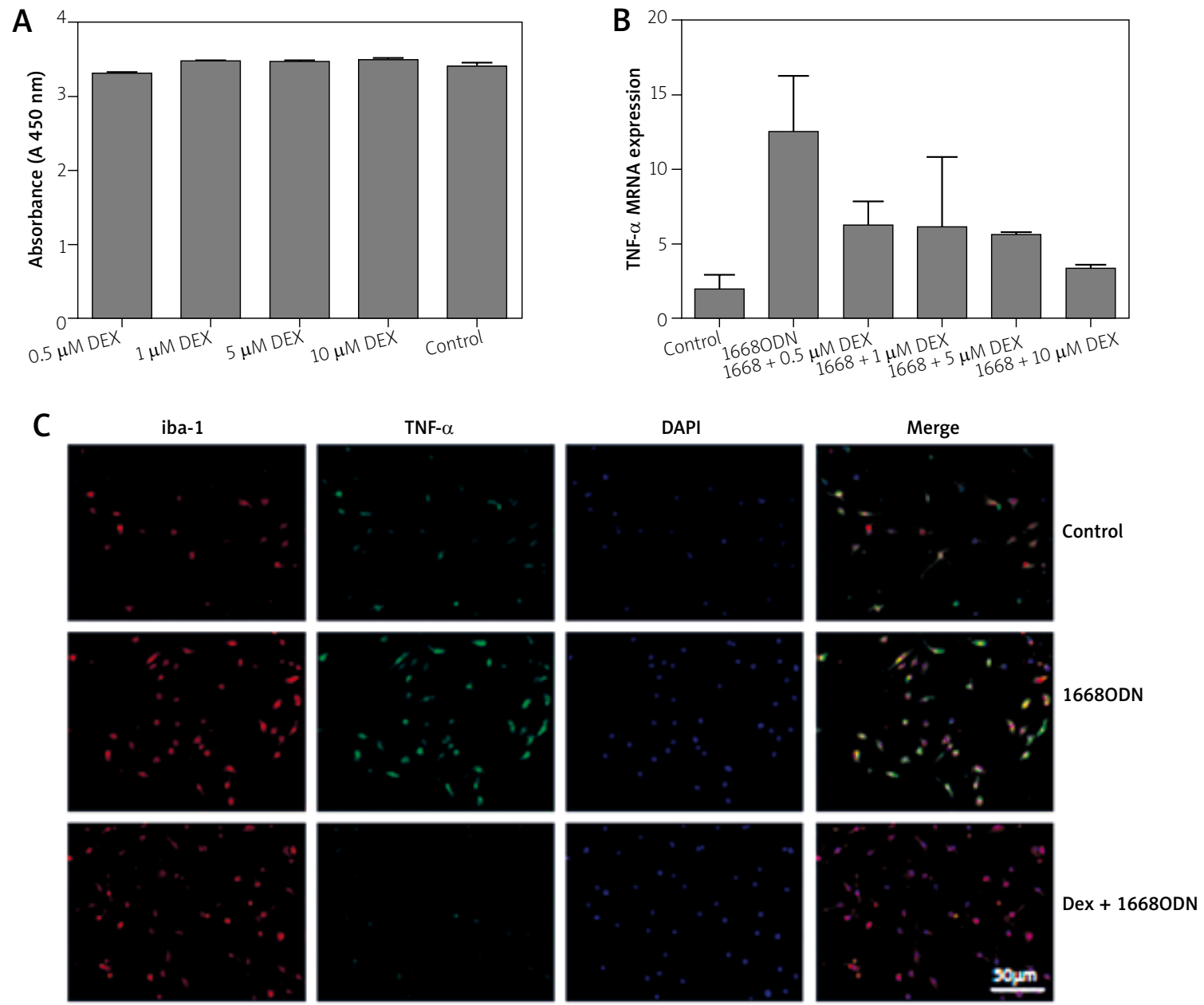

Fig. 3. Dexmedetomidine could inhibit microglia to express TNF- $\alpha$. A) The CCK 8 assay was used to evaluate the cell viability in different concentrations of $\operatorname{DEX}(0,0.5 \mu \mathrm{M}, 1.5 \mu \mathrm{M}, 10 \mu \mathrm{M})$ and control. B) The BV2 were pre-treated with different concentrations of DEX $(0.5 \mu \mathrm{M}, 1 \mu \mathrm{M}, 5 \mu \mathrm{M}, 10 \mu \mathrm{M})$ for $15 \mathrm{~min}$, then stimulated with 1OD ODN1668 for $6 \mathrm{~h}$, real-time PCR assay was used to detect the expression of TNF- $\alpha$. C) Primary mice microglia was stimulated first by DEX for $15 \mathrm{~min}$ then with 1668 ODN for $12 \mathrm{~h}$, immunofluorescence photographs demonstrated that DEX could attenuate TNF- $\alpha$ expression compared with that stimulated with ODN1668 alone.

\section{Discussion}

Our study demonstrated that DEX exerted antiinflammation effects concomitant with reduced TNF- $\alpha$ expression in microglia stimulated by unmethylated CpG via down-regulation of phosphorylated-AKT level. ODN 1668 could activate microglia to express TNF- $\alpha$, and the effect lasts for $24 \mathrm{~h}$. Different results obtained may imply that differential concentrations of ODN1668 are applied in researches. In our study, a high dose of ODN1668 contributed to the activation of microglia in a shorter time. It has been reported that PI3/AKT is required for LPS-induced microglia activation [42]. We also demonstrated both microglia activation by $\mathrm{CpG}$ DNA and DEX inhibition via PI3/AKT pathway.

Unmethylated CpG-DNA motifs, conserved microbial patterns, are recognized by pattern recognition receptors. TLR-9 is essential for activation of innate immune cells by CPG DNA. TLRS gene transcript levels are up-regulated in the central nervous system in the neuroinflammation [34]. Activated microglia by CpG DNA can secret TNF- $\alpha$ and iNOS, which could induce neurons apoptosis [25]. Compared with LPS stimulation, the IL-12 induced by CPG DNA in the CNS is a decisive cytokine in pathophysiological processes in which $\mathrm{T}$ cells are involved. Therefore, 

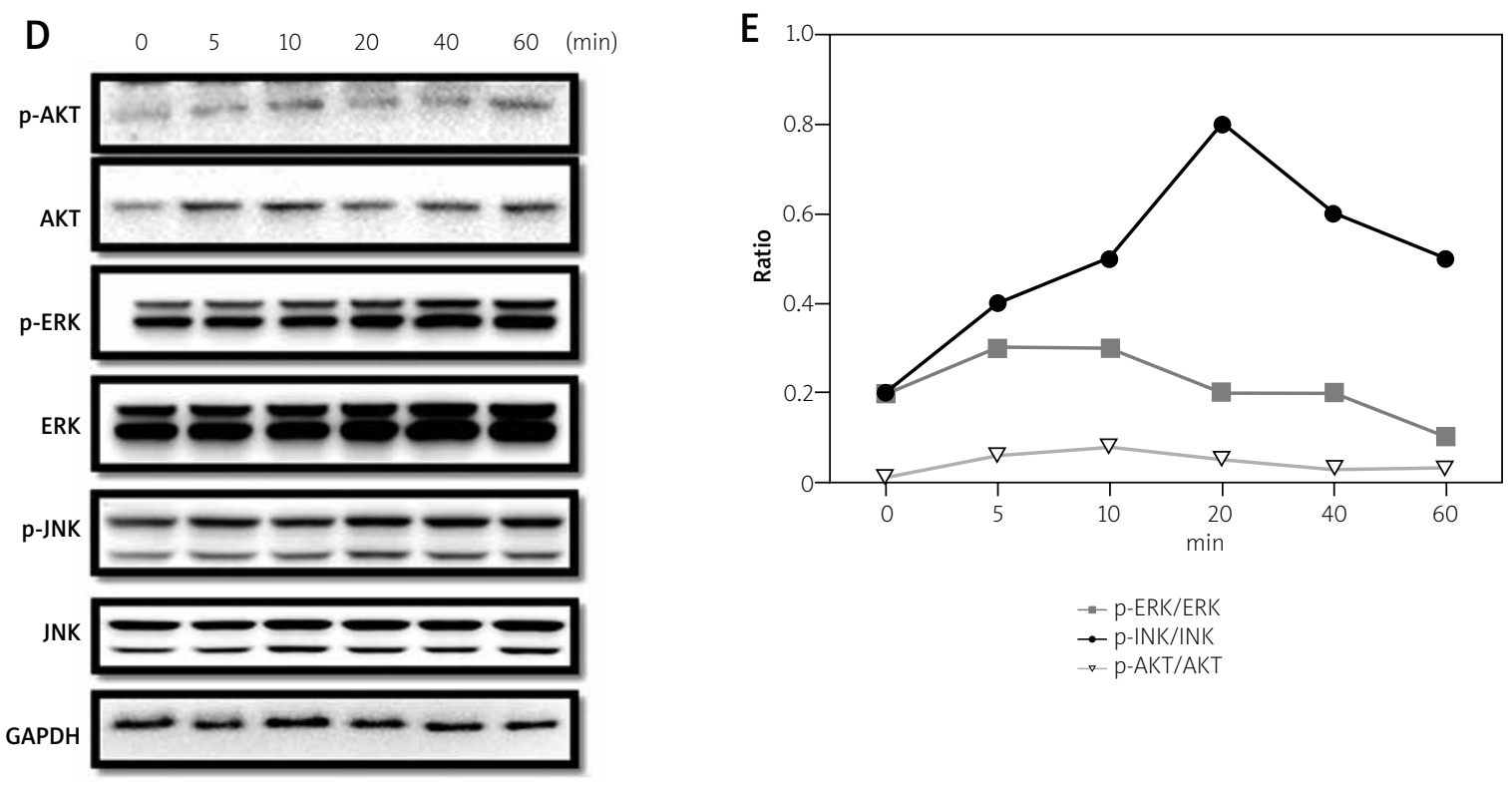

Fig. 3. Cont. Dexmedetomidine could inhibit microglia to express TNF- $\alpha$. D) Inhibition effects of DEX on ODN1668-induced phosphorylation. The representative image of western blot analysis for p-AKT, AKT, p-ERK, ERK, p-JNK and JNK that was stimulated by DEX and ODN1668. GAPDH was used as the loading control. E) Relative density of $p-A K T, A K T, p-E R K, E R K, p-J N K$ and JNK was analyzed using Photoshop, the ratio of phosphorylation and non-phosphorylation was shown in a line chart.

CpG DNA-activated microglia not only enhance T cell responses, but also induce effector molecules such as NO. However, microglia exhibit neuroprotection effects which are caused by CpG DNA in Alzheimer's disease [13]. The authors confirm that microglia express TLR9 at a high level, whereas astrocytes and neurons express it at a low level. In different diseases, activated microglia by CPG DNA play different roles [13]. In other organs and tissues, more researches about CpG DNA induced inflammation have been reported, such as lower respiratory tract inflammation [44]. Excessive TNF- $\alpha$ could cause damages in CNS, however, it is still evidenced that TNF- $\alpha$ plays a beneficial role in CNS under physiological conditions. TNF- $\alpha$ is initially to be constitutively expressed at low levels in the normal adult brains $[5,6,51]$, and plays a critical role in homeostatic synaptic scaling [47]. TNF- $\alpha$ has multiple effects in the CNS ranging from glia activation and death to neuron survival and apoptosis.

DEX is widely used in the field of anesthesia, which could cross the blood-brain barrier and play an important role in the CNS function [2,22]. Studies have shown that DEX regulates inflammatory responses, plays anti-apoptotic roles and exerts neuroprotective effects in CNS $[15,16]$. Our study demonstrated the anti-inflammation effect of DEX in unmethylated CPG induced microglia activation. With the increase in concentration of DEX, the inhibition turned more obvious. There is a report that pretreatment with DEX could decrease TLR-4 expression to disclose the protective mechanism of DEX [20]. Our result implies that DEX may also decrease the TLR-9 expression. Microglia are activated by CpG DNA via TLR-9 and phosphatidylinositol 3-kinaseAkt pathway to express proinflammatory cytokines [45], DEX could inhibit the AKT-phosphorylation to block inflammation. The result is in accordance with other researches indicating that DEX is a potent suppressor of CNS inflammation [35].

The serine/threonine kinase Akt is a central node in cell signaling downstream of growth factors, cytokines, and other cellular stimuli. It plays an important role in cell survival, growth, proliferation, angiogenesis, metabolism, and migration [31]; i.c.v. injection of ODN1668 time-reliant significantly increased AKT phosphorylation and after stimulation the levels of phosphorylation gradually increased. Pretreatment with DEX could inhibit TNF- $\alpha$ expression. Our data implied that DEX may be a potential medicine with 

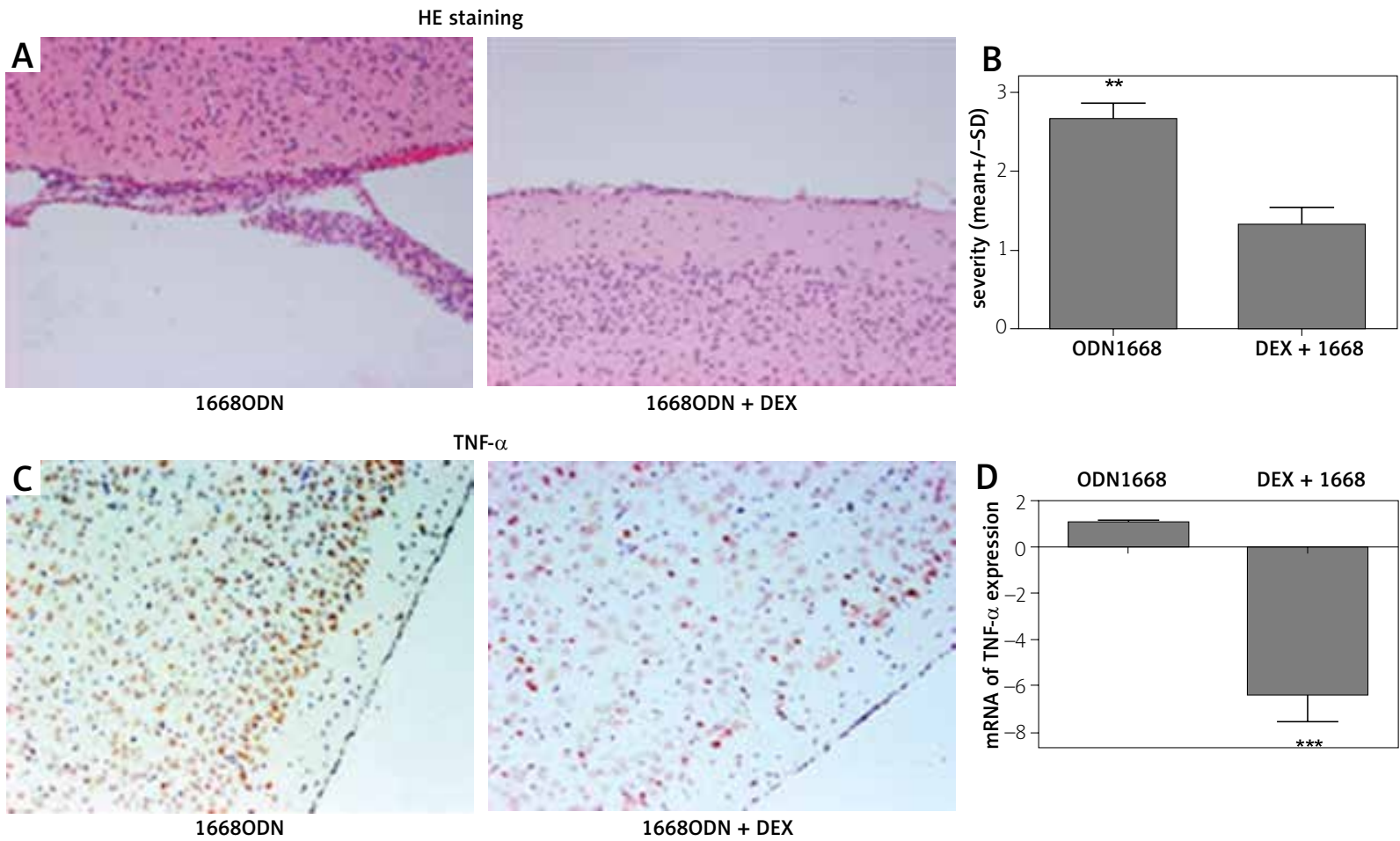

$\mathrm{NF}-\mathrm{\alpha}$

$16680 D N+D E X$


$\mathrm{E}$

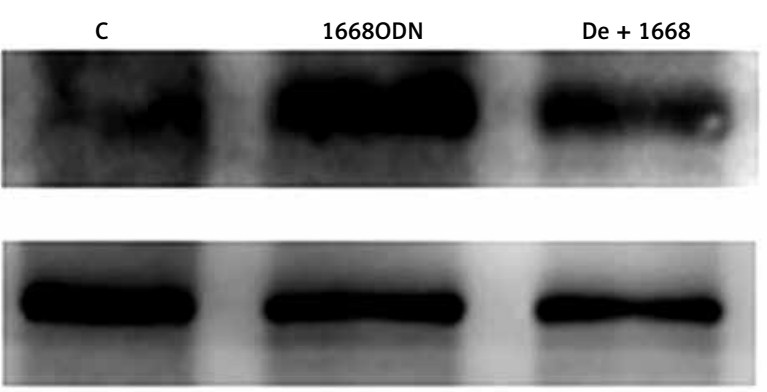

TNF- $\alpha$

GAPDH

$\mathrm{F}$

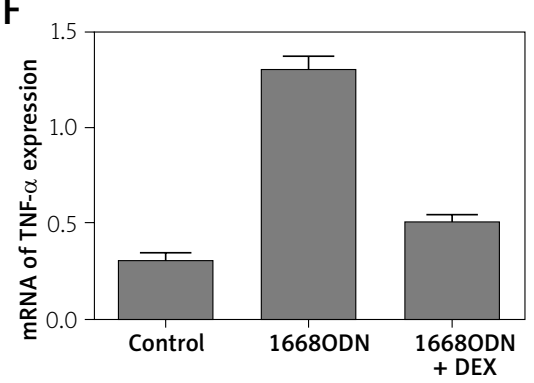

Fig. 4. Dexmedetomidine could inhibit 16680DN-induced microglia TNA- $\alpha$ expression in vivo. A) C57BL/6 mice were pre-treated with DEX $(50 \mu \mathrm{g} / \mathrm{ml}$, i.c.v.) for $30 \mathrm{~min}$, then 1OD ODN1668 was injected intracisternally for $3 \mathrm{~d}$, representative histopathology photo was shown, ODN1668 injection alone was as control $(n=5$ per group, magnification $\times 200)$. B) Score of meningitis severity in C57BL/ 6 mice treated with ODN1668 with or without DEX. ${ }^{* *} p<0.01$ compared to DEX-pretreated group. C) Immunohistochemistry analysis of TNF- $\alpha$ in the brains that were given an intracisternal injection of ODN1668 with or without DEX $(n=5$ per group, magnification $\times 200$ ). D) $3 \mathrm{~d}$ after an intracisternal injection of ODN1668 with or without pretreated with DEX for $30 \mathrm{~min}$, brain tissues were obtained and analyzed by real-time PCR. ${ }^{* *} p<0.01$ compared to DEX-pretreated group. E) Mice received DEX $(50 \mu \mathrm{g} / \mathrm{ml}$ i.c.v. $) 30$ min prior to ODN1668 treatment or not. All mice were sacrificed after $3 \mathrm{~d}$, the protein was obtained from the brains, the western blot analyzed the TNF- $\alpha$ expression. Quantitative analysis results are shown in F.

anti-inflammatory effects in CNS. In neurodegenerative diseases, MAPK pathway also plays a critical role. In Parkinson's disease (PD), JNK, ERK and p38 MAPK may contribute differentially to the dopaminergic neuronal degeneration [19]. In amyotrophic lateral sclerosis (ALS), a ligand of growth hormone secretagogue receptor (GHS-R) 1a, protects motor neurons against glutamate excitotoxicity via activating ERK1/2 and phosphatidylinositol 3-kinase (PI3K)-Akt signaling [30].

In conclusion, our results showed that clinically relevant concentration of DEX suppressed TNF- $\alpha$ 
expression in unmethylated $\mathrm{CpG}$-activated microglia and AKT and ERK pathway might play a significant role in inflammatory or anti-inflammatory effects mediated by unmethylated CPG or DEX, providing a clue of therapeutic effects of DEX in neuronal inflammatory.

\section{Acknowledgements}

This study was jointly supported by the National Natural Science Foundation of China (NO. 81270429).

\section{Disclosure}

\section{Authors report no conflict of interest.}

\section{References}

1. Barichello T, dos Santos I, Savi GD, Florentino AF, Silvestre C, Comim CM, Feier G, Sachs D, Teixeira MM, Teixeira AL, Quevedo J. Tumor necrosis factor alpha (TNF-alpha) levels in the brain and cerebrospinal fluid after meningitis induced by Streptococcus pneumoniae. Neurosci Lett 2009; 467: 217-219.

2. Benggon M, Chen H, Applegate R, Martin R, Zhang JH. Effect of dexmedetomidine on brain edema and neurological outcomes in surgical brain injury in rats. Anesthes Analg 2012; 115: 154-159.

3. Bhana N, Goa KL, McClellan KJ. Dexmedetomidine. Drugs 2000; 59: 263-268; discussion 269-270.

4. Boka G, Anglade P, Wallach D, Javoy-Agid F, Agid Y, Hirsch EC. Immunocytochemical analysis of tumor necrosis factor and its receptors in Parkinson's disease. Neurosci Lett 1994; 172: 151-154.

5. Boulanger LM. Immune proteins in brain development and synaptic plasticity. Neuron 2009; 64: 93-109.

6. Breder CD, Tsujimoto M, Terano Y, Scott DW, Saper CB. Distribution and characterization of tumor necrosis factor-alpha-like immunoreactivity in the murine central nervous system. J Comp Neurol 1993; 337: 543-567.

7. Chen Y, Miao L, Yao Y, Wu W, Wu X, Gong C, Qiu L, Chen J. Dexmedetomidine Ameliorate CLP-Induced Rat Intestinal Injury via Inhibition of Inflammation. Mediators Inflamm 2015; 2015: 918361.

8. Cowdery JS, ChaceJH, Yi AK, Krieg AM. Bacterial DNA induces NK cells to produce IFN-gamma in vivo and increases the toxicity of lipopolysaccharides. J Immunol 1996; 156: 4570-4575.

9. Dalpke AH, Schafer MK, Frey M, Zimmermann S, Tebbe J, Weihe JE, Heeg K. Immunostimulatory CpG-DNA activates murine microglia. J Immunol 2002; 168: 4854-4863.

10. de Vries HE, Blom-Roosemalen MC, van Oosten M, de Boer AG, van Berkel TJ, Breimer DD, Kuiper J. The influence of cytokines on the integrity of the blood-brain barrier in vitro. J Neuroimmunol 1996; 64: 37-43.

11. Deng GM, INilsson IM, Verdrengh M, Collins LV, Tarkowski A. Intra-articularly localized bacterial DNA containing CpG motifs induces arthritis. Nat Med 1999; 5: 702-705.

12. Deng GM, Liu ZO, Tarkowski A. Intracisternally localized bacterial DNA containing CpG motifs induces meningitis. I Immunol 2001; 167: 4616-4626.
13. Doi Y, Mizuno T, Maki Y, Jin S, Mizoguchi H, Ikeyama M, Doi M, Michikawa M, Takeuchi H, Suzumura A. Microglia activated with the toll-like receptor 9 ligand $\mathrm{CpG}$ attenuate oligomeric amyloid \{beta\} neurotoxicity in in vitro and in vivo models of Alzheimer's disease. Am J Pathol 2009; 175: 2121-2132.

14. Dutta G, Zhang P, Liu B. The lipopolysaccharide Parkinson's disease animal model: mechanistic studies and drug discovery. Fundam Clin Pharmacol 2008; 22: 453-464.

15. Engelhard K, Werner C, Eberspacher E, Bachl M, Blobner M, Hildt E, Hutzler P, Kochs E. The effect of the alpha 2-agonist dexmedetomidine and the $\mathrm{N}$-methyl-D-aspartate antagonist $\mathrm{S}(+)$-ketamine on the expression of apoptosis-regulating proteins after incomplete cerebral ischemia and reperfusion in rats. Anesthes Analg 2003; 96: 524-531.

16. Engelhard K, Werner C, Kaspar S, Mollenberg O, Blobner M, Bachl M, Kochs E. Effect of the alpha2-agonist dexmedetomidine on cerebral neurotransmitter concentrations during cerebral ischemia in rats. Anesthesiology 2002; 96: 450-457.

17. Fillit H, Ding WH, Buee L, Kalman J, Altstiel L, Lawlor B, WolfKlein G. Elevated circulating tumor necrosis factor levels in Alzheimer's disease. Neurosci Lett 1991; 129: 318-320.

18. Glimaker M, Kragsbjerg P, Forsgren M, Olcen P. Tumor necrosis factor-alpha (TNF alpha) in cerebrospinal fluid from patients with meningitis of different etiologies: high levels of TNF alpha indicate bacterial meningitis. J Inf Dis 1993; 167: 882-889.

19. Goedert M. Alpha-synuclein and neurodegenerative diseases. Nat Rev Neurosci 2001; 2: 492-501.

20. Gu J, Sun P, Zhao H, Watts HR, Sanders RD, Terrando N, Xia P, Maze M, Ma D. Dexmedetomidine provides renoprotection against ischemia-reperfusion injury in mice. Crit Care 2011; 15: R153.

21. Gutierrez EG, Banks W, Kastin A. Murine tumor necrosis factor alpha is transported from blood to brain in the mouse. J Neuroimmunol 1993; 47: 169-176.

22. Hayashi Y, Sumikawa K, Maze M, Yamatodani A, Kamibayashi T, Kuro M, Yoshiya I. Dexmedetomidine prevents epinephrineinduced arrhythmias through stimulation of central alpha 2 adrenoceptors in halothane-anesthetized dogs. Anesthesiology 1991; 75: 113-117.

23. Hemmi H, Takeuchi O, Kawai T, Kaisho T, Sato S, Sanjo H, Matsumoto M, Hoshino K, Wagner H, Takeda K, Akira S. A Toll-like receptor recognizes bacterial DNA. Nature 2000; 408: 740-745.

24. Hofman FM, Hinton DR, Johnson K, Merrill JE. Tumor necrosis factor identified in multiple sclerosis brain. J Exp Med 1989; 170: 607-612

25. Iliev Al, Stringaris AK, Nau R, Neumann H. Neuronal injury mediated via stimulation of microglial toll-like receptor-9 (TLR9). FASEB J 2004; 18: 412-414

26. Klinman DM, Yi AK, Beaucage SL, Conover J, Krieg AM. CpG motifs present in bacteria DNA rapidly induce lymphocytes to secrete interleukin 6, interleukin 12, and interferon gamma. Proc Natl Acad Sci U S A 1996; 93: 2879-2883.

27. Krieg AM, Yi AK, Matson S, Waldschmidt TJ, Bishop GA, Teasdale R, Koretzky GA, Klinman DM. CpG motifs in bacterial DNA trigger direct B-cell activation. Nature 1995; 374: 546-549.

28. Lee CY, Landreth GE. The role of microglia in amyloid clearance from the AD brain. J Neural Transm 2010; 117: 949-960. 
29. Leist TP, Frei K, Kam-Hansen S, Zinkernagel RM, Fontana A. Tumor necrosis factor alpha in cerebrospinal fluid during bacterial, but not viral, meningitis. Evaluation in murine model infections and in patients. J Exp Med 1988; 167: 1743-1748.

30. Lim E, Lee S, Li E, Kim Y, Park S. Ghrelin protects spinal cord motoneurons against chronic glutamate-induced excitotoxicity via ERK1/2 and phosphatidylinositol-3-kinase/Akt/glycogen synthase kinase-3beta pathways. Exp Neurol 2011; 230: 114-122.

31. Manning BD, Cantley LC. AKT/PKB signaling: navigating downstream. Cell 2007; 129: 1261-1274.

32. Mathes AL, Rice L, Affandi AJ, DiMarzio M, Rifkin IR, Stifano G, Christmann RB, Lafyatis R. CpGB DNA activates dermal macrophages and specifically recruits inflammatory monocytes into the skin. Exp Dermatol 2015; 24: 133-139.

33. Messina JP, Gilkeson GS, Pisetsky DS. Stimulation of in vitro murine lymphocyte proliferation by bacterial DNA. I Immuno 1991; 147: 1759-1764.

34. Nguyen MD, Julien JP, Rivest S. Innate immunity: the missing link in neuroprotection and neurodegeneration? Nat Rev Neurosci 2002; 3: 216-227.

35. Peng M, Wang YL, Wang CY, Chen C. Dexmedetomidine attenuates lipopolysaccharide-induced proinflammatory response in primary microglia. J Surg Res 2013; 179: e219-225.

36. Perry VH, Nicoll JA, Holmes C. Microglia in neurodegenerative disease. Nat Rev Neurol 2010; 6: 193-201.

37. Pober JS, Cotran RS. Cytokines and endothelial cell biology. Physiol Rev 1990; 70: 427-451.

38. Probert L, Akassoglou K, Pasparakis M, Kontogeorgos G, Kollias G. Spontaneous inflammatory demyelinating disease in transgenic mice showing central nervous system-specific expression of tumor necrosis factor alpha. Proc Nat Acad Sci USA 1995; 92 11294-11298.

39. Quagliarello VJ, Wispelwey B, Long WJ Jr, Scheld WM. Recombinant human interleukin-1 induces meningitis and blood brain barrier injury in the rat. Characterization and comparison with tumor necrosis factor. J Clin Invest 1991; 87: 1360-1366.

40. Ramilo O, Saez-Llorens X, Mertsola J, Jafari H, Olsen KD, Hansen EJ, Yoshinaga M, Ohkawara S, Nariuchi H, McCracken GH Jr. Tumor necrosis factor alpha/cachectin and interleukin 1 beta initiate meningeal inflammation. J Exp Med 1990; 172: 497-507.

41. Rock RB, Gekker G, Hu S, Sheng WS, Cheeran M, Lokensgard JR, Peterson PK. Role of microglia in central nervous system infections. Clin Microbiol Rev 2004; 17: 942-964.

42. Saponaro C, Cianciulli A, Calvello R, Dragone T, Iacobazzi F, Panaro MA. The PI3K/Akt pathway is required for LPS activation of microglial cells. Immunopharmacol Immunotoxicol 2012; 34 858-865.

43. Sawada M, Kondo N, Suzumura A, Marunouchi T. Production of tumor necrosis factor-alpha by microglia and astrocytes in culture. Brain Res 1989; 491: 394-397.

44. Schwartz DA, Quinn TJ, Thorne PS, Sayeed S, Yi AK, Krieg AM. CpG motifs in bacterial DNA cause inflammation in the lower respiratory tract. J Clin Invest 1997; 100: 68-73.

45. Sester DP, Brion K, Trieu A, Goodridge H, Roberts TL, Dunn J, Hume D, Stacey KJ, Sweet MJ. CpG DNA activates survival in murine macrophages through TLR9 and the phosphatidylinositol 3-kinase-Akt pathway. J Immunol 2006; 177: 4473-4480.
46. Sparwasser T, Miethke T, Lipford G, Erdmann A, Hacker H, Heeg K, Wagner H. Macrophages sense pathogens via DNA motifs: induction of tumor necrosis factor-alpha-mediated shock. Eur I Immunol 1997; 27: 1671-1679.

47. Stellwagen D, Malenka RC. Synaptic scaling mediated by glial TNF-alpha. Nature 2006; 440: 1054-1059.

48. Takeshita S, Takeshita F, Haddad DE, Janabi N, Klinman DM. Activation of microglia and astrocytes by CpG oligodeoxynucleotides. Neuroreport 2001; 12: 3029-3032.

49. Vassalli P. The pathophysiology of tumor necrosis factors. Ann Rev Immunol 1992; 10: 411-452.

50. Vincenti MP, Burrell TA, Taffet SM. Regulation of NF-kappa B activity in murine macrophages: effect of bacterial lipopolysaccharide and phorbol ester. J Cell Physiol 1992; 150: 204-213.

51. Vitkovic L, Bockaert J, Jacque C. "Inflammatory" cytokines: neuromodulators in normal brain? J Neurochem 2000; 74: 457-471.

52. Wagner $\mathrm{H}$. Bacterial CpG DNA activates immune cells to signal infectious danger. Adv Immunol 1999; 73: 329-368.

53. Xu Y, Zhang R, Li C, Yin X, Lv C, Wang Y, Zhao W, Zhang X. Dexmedetomidine attenuates acute lung injury induced by lipopolysaccharide in mouse through inhibition of MAPK pathway. Fund Clin Pharmacol 2015; 29: 462-471.

54. Yang D, Hong JH. Dexmedetomidine Modulates Histamine-induced $\mathrm{Ca}(2+)$ Signaling and Pro-inflammatory Cytokine Expression. Korean J Physiol Pharmacol 2015; 19: 413-420.

55. Yi AK, Klinman DM, Martin TL, Matson S, Krieg AM. Rapid immune activation by $\mathrm{CpG}$ motifs in bacterial DNA. Systemic induction of IL-6 transcription through an antioxidant-sensitive pathway. J Immunol 1996; 157: 5394-5402.

56. Zhang S, Shao SY, Song XY, Xia CY, Yang Y, Zhang PC, Chen NH. Protective effects of Forsythia suspense extract with antioxidant and anti-inflammatory properties in a model of rotenone induced neurotoxicity. Neurotoxicology 2016; 52: 72-83.

57. Zhang X, Wang J, Qian W, Zhao J, Sun L, Qian Y, Xiao H. Dexmedetomidine inhibits tumor necrosis factor-alpha and interleukin 6 in lipopolysaccharide-stimulated astrocytes by suppression of c-Jun N-terminal kinases. Inflammation 2014; 37: 942-949.

58. Zhou H, Andonegui G, Wong CH, Kubes P. Role of endothelial TLR4 for neutrophil recruitment into central nervous system microvessels in systemic inflammation. I Immunol 2009; 183: 5244-5250. 